\title{
Plyometric Exercises from a Knee Anterior Cruciate Ligament Prevention Program on the Rate of Isometric Torque Development and Vertical Jump Height
}

Jeffrey R. Doeringer

Nova Southeastern University, jdoeringer@nova.edu

Sam Johnson

Oregon State University

Marc Norcorss

Oregon State University

Mark Hoffman

Oregon State University

Follow this and additional works at: https://nsuworks.nova.edu/ijahsp

Part of the Sports Sciences Commons

\section{Recommended Citation}

Doeringer JR, Johnson S, Norcorss M, Hoffman M. Plyometric Exercises from a Knee Anterior Cruciate Ligament Prevention Program on the Rate of Isometric Torque Development and Vertical Jump Height. The Internet Journal of Allied Health Sciences and Practice. 2018 Jan 01;16(1), Article 6.

This Manuscript is brought to you for free and open access by the College of Health Care Sciences at NSUWorks. It has been accepted for inclusion in Internet Journal of Allied Health Sciences and Practice by an authorized editor of NSUWorks. For more information, please contact nsuworks@nova.edu. 


\title{
Plyometric Exercises from a Knee Anterior Cruciate Ligament Prevention Program on the Rate of Isometric Torque Development and Vertical Jump Height
}

\begin{abstract}
Purpose: Plyometric exercises are incorporated in anterior cruciate ligament injures of the knee (ACL) injury prevention programs that have effectively decreased risk factors for anterior cruciate ligament injures of the knee injuries, but the impact on the rate of isometric torque development of the musculature of the knee is unclear. The purpose of this study was to determine the effects of a 6-week plyometric program pulled from a commonly utilized anterior cruciate ligament injures of the knee injury prevention program on rate of isometric torque development (RTD) in healthy active females.

Methods: College-aged participants were randomly split into two different groups (16-plyometric training and 15 -control). Plyometric exercises included $180^{\circ}$ jumps, bounding for distance, bounding in place, broad jump-stick, cone jumps, hop - hop stick, jump into bounding, jump - jump - jump vertical jump, mattress jumps, scissors jump, single-legged jumps for distance, squat jumps, step-jump up-down-vertical jump, tuck jumps, and wall jumps. Participants in the training group performed the exercises three times a week on alternating days, for 30-minute sessions. All participants performed a vertical jump measurement and completed maximum voluntary isometric contractions (MVICs) of ankle plantar flexion, knee extension, and knee flexion rate of torque development.

Results: There was a main effect of session for plantar flexion rate of torque development time windows and vertical jump. The analysis revealed no significant differences for group by session interactions for any other rate of torque development measurement or the vertical jump.

Conclusions: Plyometric exercises utilized from an anterior cruciate ligament injures of the knee injury prevention program did not change lower body isometric torque development or vertical jump height of active females. Since the plyometric training did not improve vertical jump, the training may not have been performed vigorous enough for the participants to cause a neuromuscular adaptation. Based on findings, 6-weeks of plyometric training from an isolated ACL injury prevention program should not be used to increase the vertical jump of healthy, active females.
\end{abstract}

\section{Author Bio(s)}

Jeffrey R. Doeringer PhD, ATC is an Assistant Professor of Department of Health and Human Performance in the College of Health Care Sciences at Nova Southeastern University. He is a licensed Athletic Trainer in the state of Florida.

Sam Johnson PhD, ATC, CSCS is a Clinical Assistant Professor at Oregon State University.

Marc F. Norcross PhD, ATC is an Assistant Professor at Oregon State University.

Mark A. Hoffman PhD, ATC, FACSM is a Vice Provost for International Programs at Oregon State University. 


\title{
TIAHSP \\ The Internet Joưnal of Allied Health Sciences and Practice
}

Dedicated to allied health professional practice and education

Vol. 16 No. 1 ISSN 1540-580X

\section{Plyometric Exercises from a Knee Anterior Cruciate Ligament Prevention Program on the Rate of Isometric Torque Development and Vertical Jump Height}

\author{
Jeffrey R. Doeringer, PhD, ATC 1 \\ Sam Johnson, PhD, ATC, CSCS² \\ Marc F. Norcorss, PhD, ATC ${ }^{2}$ \\ Mark A. Hoffman, PhD, ATC, FACSM² \\ Nova Southeastern University \\ Oregon State University \\ United States
}

\begin{abstract}
Purpose: Plyometric exercises are incorporated in anterior cruciate ligament injures of the knee (ACL) injury prevention programs that have effectively decreased risk factors for anterior cruciate ligament injures of the knee injuries, but the impact on the rate of isometric torque development of the musculature of the knee is unclear. The purpose of this study was to determine the effects of a six-week plyometric program pulled from a commonly utilized anterior cruciate ligament injures of the knee injury prevention program on rate of isometric torque development (RTD) in healthy active women. Methods: College-aged participants were randomly split into two different groups (16 for plyometric training and 15 for control). Plyometric exercises included $180^{\circ}$ jumps, bounding for distance, bounding in place, broad jump-stick, cone jumps, hop-hop stick, jump into bounding, jump-jumpjump vertical jump, mattress jumps, scissors jump, single-legged jumps for distance, squat jumps, step-jump up-down-vertical jumps, tuck jumps, and wall jumps. Participants in the training group performed the exercises three times a week on alternating days, for 30-minute sessions. All participants performed a vertical jump measurement and completed maximum voluntary isometric contractions (MVICs) of ankle plantar flexion, knee extension, and knee flexion rate of torque development. Results: There was a main effect of session for plantar flexion rate of torque development time windows and vertical jump. The analysis did not indicate any significant differences for group by session interactions for any other rate of torque development measurement or the vertical jump. Conclusions: Plyometric exercises utilized from an anterior cruciate ligament injures of the knee injury prevention program did not change lower body isometric torque development or vertical jump height of active female participants. Because the plyometric training did not improve vertical jump, the training may not have been performed vigorous enough for the participants to cause a neuromuscular adaptation. Based on findings, 6 weeks of plyometric training from an isolated ACL injury prevention program should not be used to increase the vertical jump of healthy, active women.
\end{abstract}

\section{INTRODUCTION}

Plyometric training was originally designed for power-trained athletes to improve their performance in sport. ${ }^{1}$ During plyometric exercises, the participants typically attempt to produce rapid maximal force. ${ }^{2-6}$ Plyometrics induce neural control improvements, causing change to muscle function and performance. ${ }^{2}$ In addition, plyometrics increases the neural drive and muscle activation strategies to improve muscle strength and speed. ${ }^{2,7}$

Studies involving plyometrics have been focused on the production of powerful movements to improve speed and vertical jump. ${ }^{1,2,8-10}$ However, more recent investigations have been focused on the role of plyometrics in injury prevention. ${ }^{11-16}$ The authors reported the anterior cruciate ligament of the knee (ACL) prevention program to be effective in increasing hamstring muscle activation in both legs. ${ }^{11,16}$ Plyometrics incorporated in ACL prevention programs is thought to increase muscle force production to protect the knee from injury. ${ }^{11,16-19}$ It is unknown if the plyometric component is the primary cause for these positive 
changes from an $\mathrm{ACL}$ prevention program. A quicker hamstring muscle contraction may provide additional knee protection during functional movements. ${ }^{16} \mathrm{In}$ addition, plyometric training could increase activation of all lower extremity muscles to protect the knee during the explosive movements.

The rate of torque development (RTD) is used to evaluate how quickly a muscle can produce force. ${ }^{20,21}$ An increase in RTD of the knee musculature indicates the muscles are able to activate more quickly to aid as a protective stabilizing mechanism. ${ }^{21,22}$ In one example, the rate of force development (RFD) of women and men elite soccer players was measured for both the hamstring and quadricep muscle groups. ${ }^{21} \mathrm{An}$ imbalance between the hamstring and quadricep muscles in which the hamstring muscles were much weaker and developed torque more slowly, indicated that these athletes were at risk of a noncontact $\mathrm{ACL}$ injury. ${ }^{21}$ Zebis et al measured a RFD hamstring-to-quadricep $(\mathrm{H}: \mathrm{Q})$ ratio deficit during the first $50 \mathrm{~ms}$ of initial contraction of a side-cutting maneuver. ${ }^{21}$ This ratio deficit indicated the hamstrings activated more slowly to protect the knee during the initial $50 \mathrm{~ms}$ window. ${ }^{21}$ The plantar flexion action is a component of triple extension for vertical jump and torque production with plyometric exercises. ${ }^{8}$ Plyometric training could increase the rate of torque produced in the muscles around the knee during functional tasks due to the dynamic and functional program. ${ }^{20,23-25}$

The objective of this study was to determine the effect of plyometric exercises from a commonly used ACL prevention program on vertical jump performance and maximum voluntary isometric contractions (MVICs) RTD during plantar flexion, knee extension, and knee flexion in healthy active women.

\section{METHODS}

\section{Participants}

Thirty-one healthy, college-aged, female students participated in the study. Sixteen female students participated in a plyometric training group (age $=22.5 \pm 3.2$ years, height $=167.8 \pm 7.6 \mathrm{~cm}$, mass $=64.5 \pm 7.4 \mathrm{~kg}$ ) and 15 in a control group (age $=22.7 \pm$ 2.3 years, height $=166.2 \pm 6.4 \mathrm{~cm}$, mass $=65.4 \pm 6.3 \mathrm{~kg}$ ). Participants were pseudo-randomized into either a plyometric training $(n=16)$ or a control group $(n=15)$ by blindly picking a group assignment out of a bag. To participate in the study, participants were required to not be a current athlete but physically active 3 times a week for approximately 30 minutes. A list of the exclusion criteria is presented in Table 1. All participants provided written consent, approved by Oregon State University's Institutional Review Board for the protection of human participants before participating in the study.

Table 1. Exclusion Criteria.

\section{EXCLUSION CRITERIA}

- Known neurological disorder

- Injury to the lower extremity in the previous 6 months

- Concluded a season of basketball or volleyball within the last 12 months Participating currently in a sport

- Previous involvement in an ACL prevention program

- Previous involvement in a four-week or longer plyometric training program Plan to change their personal workout during the course of the study

\section{Procedures}

Participants attended preintervention and postintervention testing sessions separated by approximately 6 weeks. The plyometric training group performed 6 weeks of jumping exercises in the laboratory. The control group members were asked not to change their daily physical activities for the duration of the study during the 6 weeks between testing sessions. Each testing session began with a standard warm-up, including 15 jumping jacks and 15 bodyweight squats before beginning testing began. During each testing session, participants were measured for maximal vertical jump and for rate of torque development. The RTD were assessed during the time windows of 0 to $50 \mathrm{~ms}, 0$ to $100 \mathrm{~ms}, 0$ to $150 \mathrm{~ms}, 0$ to $200 \mathrm{~ms}$, and 0 to $250 \mathrm{~ms}$. 


\section{Vertical Jump Measurement}

Participants performed maximal vertical jumps measured using a Vertec Jump System. First, the height of the subject's straightarm reach above her head with the Vertec Jump System was measured. To perform the test, the subject stood with her feet shoulder width apart and when ready, performed a counter movement jump to reach as high as possible on each vertical jump trial. During the vertical jmp the subject reached with one hand to touch and move the measurement markers on the Vertec Jump System. The subject performed 3 maximal vertical jumps per session with the best jump used for the data analysis. Vertical jumps were measured by the difference in distance between the subject's reach height from her maximal vertical jump. Baseline and post measurements were compared for both groups.

\section{Rate of Torque Development Measurements}

Participants were measured on RTD for plantar flexion, knee extension, and knee flexion. All testing was conducted on the dominant leg as determined by her preferred kicking leg. The RTD was performed on the Biodex System III (Biodex Systems, Inc., Shirley, NY). For ankle plantar flexion, participants were seated in the Biodex dynamometer in a semi-reclined position. The foot of the subject's dominant leg was placed in the footplate and secured with straps. The knee was positioned at $60^{\circ}$ of flexion and the ankle was positioned at $0^{\circ}$ of plantar flexion. The verbal command of "push as hard and as fast as you can" was given before the subject performed maximal voluntary isometric contraction. A light was used to notify the subject when to begin the trial and to hold the MVIC for 5 seconds. The participants performed 3 rapid maximal isometric plantar flexion contractions with a minute rest between each trial.

Next, participants performed knee extension and knee flexion MVIC. The chair was positioned so the subject's hip was flexed to approximately $90^{\circ}$ and the knee flexed at $60^{\circ}$. Again, a verbal command of "push as hard and as fast as you can" was given before each trial. A light was used to notify the subject when to begin the trial. The subject performed three rapid maximal isometric knee extension contractions with a minute rest between each trial. Then three rapid maximal isometric knee flexion contractions were performed with a minute rest between each trial. Most of the RTD data collection was based on a previous study. ${ }^{20}$

Rate of torque development was measured during maximal isometric contraction for plantar flexion, knee extension, and knee flexion. Initial torque onset was defined as $2.5 \%$ of MVIC. All RTD data were sampled at $2000 \mathrm{~Hz}$. Limb weight was adjusted into voltage output and a DC bias was used to correct the signal. RTD data were low-pass-filtered with the cutoff frequency of $350 \mathrm{~Hz}$ and high-pass-filtered with the cutoff frequency of $10 \mathrm{~Hz}$. The data was smoothed with root mean square and processed using a fourth-order recursive filter. Bodyweight $\left(\mathrm{kg}^{*} 9.81\right)$ multiplied by height $(\mathrm{cm})$ as represented by $(\mathrm{BWxHt})^{1}$ was used to normalize all RTD data. Body mass and height to compare participants across the study equally normalized the RTD.

\section{Plyometric Training}

The chosen plyometric training program aligned with the plyometric section of the Jump Training program. ${ }^{16}$ Plyometric exercises included $180^{\circ}$ jumps, bounding for distance, bounding in place, broad jump-stick, cone jumps, hop-hop stick, jump into bounding, jump-jump-jump vertical jump, mattress jumps, scissors jump, single-legged jumps for distance, squat jumps, step-jump updown-vertical jump, tuck jumps, and wall jumps. Participants in the training group performed the exercises 3 times a week on alternating days for 30-minute sessions. There were 3 phases for this program with two-week duration, changing some of the exercises or changing the duration or repetitions per exercises that did not change. If a subject missed more than 4 training sessions, less than $78 \%$ attendance, she was excluded from the postintervention testing session. In the current study, the participants reported to the laboratory to perform the training session under direct supervision of a research study team member. The investigators instructed the participants and provided feedback for exercises, including (1) correct posture and body alignment, (2) jumping straight up with no excessive movement, (3) soft landings with bent knees, and (4) instant reloading for preparation of the next jump. All exercises were demonstrated and the participants were thoroughly instructed on proper techniques.

\section{Statistical Analysis}

The dependent variables were vertical jump; plantar flexion RTD; knee extension RTD; and knee flexion RTD at 0 to $50 \mathrm{~ms}, 0$ to $100 \mathrm{~ms}, 0$ to $150 \mathrm{~ms}, 0$ to $200 \mathrm{~ms}$, and 0 to $250 \mathrm{~ms}$. A 2 (group) x 2 (session) mixed model ANOVA was implemented for each dependent variable using the best of each measurement. An alpha level of .05 was used for all analyses. All data were explored for extreme outliers (> 3 standard deviations from the mean). All statistical analyses were performed using SPSS software, version 19 (SPSS, Inc. Chicago, IL). 


\section{RESULTS}

The plyometric training group participants attended $92 \%$ of the training sessions, and no subject missed more than 4 training sessions. All RTD and vertical jump means and standard deviations are presented in Table 2.

The $2 \times 2$ mixed model ANOVAs indicated no significant group $x$ session interaction or group main effect for all variables. There was a significant session main effect $(p<.001$; pre $=35.02 \pm 4.99$, post $=36.96 \pm 5.22)$ for vertical jump but not between groups $(p>.05$, plyometric pre $=35.24 \pm 4.16$, plyometric

post $=38.02 \pm 4.08$, control pre $=34.8 \pm 5.82$, control post $=35.90 \pm 6.36)$. Plantar flexion RTD had a significant session main effect $(p<.05)$, indicating a similar increase in RTD for all time windows (See Table 3 ).

Table 2. Preintervention and Postintervention Means and Standard Deviations

\begin{tabular}{|c|c|c|c|c|}
\hline & Plyometric PRE & POST & Control PRE & POST \\
\hline PFRTD 0-50 & $0.13 \pm 0.05$ & $0.20 \pm 0.07$ & $0.15 \pm 0.07$ & $0.19 \pm 0.11$ \\
\hline PFRTD 0-100 & $0.17 \pm 0.08$ & $0.24 \pm 0.10$ & $0.19 \pm 0.08$ & $0.22 \pm 0.13$ \\
\hline PFRTD 0-150 & $0.17 \pm 0.08$ & $0.23 \pm 0.10$ & $0.18 \pm 0.07$ & $0.21 \pm 0.13$ \\
\hline PFRTD 0-200 & $0.15 \pm 0.08$ & $0.21 \pm 0.09$ & $0.15 \pm 0.06$ & $0.18 \pm 0.12$ \\
\hline PFRTD 0-250 & $0.13 \pm 0.07$ & $0.18 \pm 0.08$ & $0.13 \pm 0.05$ & $0.16 \pm 0.10$ \\
\hline KERTD 0-50 & $0.31 \pm 0.12$ & $0.36 \pm 0.14$ & $0.38 \pm 0.23$ & $0.38 \pm 0.24$ \\
\hline KERTD 0-100 & $0.46 \pm 0.15$ & $0.52 \pm 0.18$ & $0.53 \pm 0.30$ & $0.53 \pm 0.30$ \\
\hline KERTD 0-150 & $0.45 \pm 0.12$ & $0.50 \pm 0.16$ & $0.48 \pm 0.24$ & $0.47 \pm 0.22$ \\
\hline KERTD 0-200 & $0.39 \pm 0.09$ & $0.42 \pm 0.14$ & $0.41 \pm 0.17$ & $0.39 \pm 0.16$ \\
\hline KERTD 0-250 & $0.33 \pm 0.08$ & $0.36 \pm 0.12$ & $0.35 \pm 0.13$ & $0.33 \pm 0.13$ \\
\hline KFRTD 0-50 & $0.15 \pm 0.06$ & $0.19 \pm 0.08$ & $0.18 \pm 0.09$ & $0.18 \pm 0.09$ \\
\hline KFRTD 0-100 & $0.18 \pm 0.05$ & $0.22 \pm 0.07$ & $0.21 \pm 0.08$ & $0.22 \pm 0.10$ \\
\hline KFRTD 0-150 & $0.20 \pm 0.06$ & $0.21 \pm 0.04$ & $0.20 \pm 0.06$ & $0.20 \pm 0.07$ \\
\hline KFRTD 0-200 & $0.20 \pm 0.06$ & $0.20 \pm 0.04$ & $0.19 \pm 0.06$ & $0.18 \pm 0.06$ \\
\hline KFRTD 0-250 & $0.18 \pm 0.05$ & $0.17 \pm 0.03$ & $0.16 \pm 0.05$ & $0.15 \pm 0.04$ \\
\hline
\end{tabular}

Abbreviations: PF, Plantar Flexion; KE, Knee Extension; KF, Knee Flexion; RTD, Rate of Torque Development; PRE, Pre Intervention; POST, Post Intervention; Plyometric, Plyometric Training Group; Control, Control Group. RTD values are means \pm standard deviations of $\left(\mathrm{Nm} / \mathrm{s}^{*}(\mathrm{BWxHt})-1\right)$ which are magnified by 100

Table 3. Plantar Flexion RTD Session Main Effect for Each Time Window

\begin{tabular}{|l|l|l|l|}
\hline & PRE & POST & $p$ value \\
\hline PFRTD 0-50 & $0.14 \pm 0.06$ & $0.19 \pm 0.09$ & $p<.001$ \\
\hline PFRTD 0-100 & $0.17 \pm 0.08$ & $0.23 \pm 0.11$ & $p=.003$ \\
\hline PFRTD 0-150 & $0.17 \pm 0.08$ & $0.22 \pm 0.12$ & $p=.006$ \\
\hline PFRTD 0-200 & $0.15 \pm 0.07$ & $0.19 \pm 0.11$ & $p=.004$ \\
\hline PFRTD 0-250 & $0.13 \pm 0.07$ & $0.17 \pm 0.09$ & $p=.003$ \\
\hline
\end{tabular}

Abbreviations: PF, Plantar Flexion; RTD, Rate of Torque Development; PRE, Preintervention; POST, Postintervention; RTD values are means \pm standard deviations of $\left(\mathrm{Nm} / \mathrm{s}^{*}(\mathrm{BWXHt})-1\right)$, which are magnified by 100 ; Vertical Jump values are means \pm standard deviations of $(\mathrm{cm})$.

\section{DISCUSSION}

Plyometric exercises involve rapid and powerful movements to improve performance.8-10 In the past 15 years, plyometrics have been incorporated in ACL prevention programs to reduce injuries.11-15 Plyometric training is expected to increase the rate of torque produced in muscles around the knee to protect the knee from injury.11,17-19 The current study was conducted to determine if participants who participated in plyometric training would demonstrate changes in rate of torque development following the training program in healthy, active women. 
In a meta-analysis, plyometric training was demonstrated to have increased strength output and verticaljump improvements in individuals with poor and good fitness levels in both genders. ${ }^{1}$ In addition, plyometric exercises increased performance in athletic and non-athletic subject populations. ${ }^{1}$ Plyometric training is more functional and has greater intensity of exercises beyond basic resistance strength training to improve performance. ${ }^{2}$ In the current study, resistance strength training was not included; however, it was expected that RTD would improve following a plyometric training program. In the past, resistance and sensorimotor training have both been shown to cause increases in RTD. 10,20,23-25,27 Therefore, it was expected that plyometric training would show similar results in the current study.

Following plyometric training, there were no significant plantar flexor RTD changes between groups. There was a significant session main effect for all time windows. One reason for this session main effect may have been a learning effect from preintervention to postintervention sessions. The participants were positioned in which they may have attempted to use their entire leg to perform triple extension. The participants may have attempted to use their entire leg more in the postintervention session as a learning effect. Plantar flexion action is not a standard movement pattern commonly isolated during strength training or other functional activities. The participants may have felt more comfortable performing this action during the second testing session, which allowed for an increased RTD output for both groups. The plyometric training group was expected to show increased RTD output following the intervention. Plyometric training included various hopping and jumping exercises, which required the use of the gastrocnemius and soleus muscle. It has been reported that ankle plantar flexors (gastrocnemius and soleus) produce $25 \%$ of total stored energy in the lower extremity during the propulsion of a jump. ${ }^{4}$ The stored energy in muscle tendons help increase the performance during jumping exercises that would lead to higher jumps and increases in muscle strength following training..$^{3-6}$

In the current study, at least half of the exercises in the plyometric training protocol required the use of plantar flexion and not the entire lower extremity. One potential reason there was not a significant difference in plantar flexion RTD following plyometric training was because the testing position of the lower leg was not in the optimal position to record the gastrocnemius muscle. Plantar flexion RTD was tested with the knee flexed at $60^{\circ}$, which included the soleus and gastrocnemius muscle torque. Plyometric exercises are more effective on fast-twitch muscle fiber (ie gastrocnemius) because of the amount of energy used is proportional to the amount of energy stored during the quicker movements. ${ }^{28}$ Slow-twitch muscle fibers (ie soleus) are more responsive to movements that require a longer and slower stretch of the muscle. ${ }^{28}$ The gastrocnemius muscle would be most likely influenced by the plyometric training program. ${ }^{3-6}$

On the other hand, gluteus maximus, quadricep, and hamstring muscles account for the other $75 \%$ of stored energy in the lower extremity during the propulsion of a jump. ${ }^{4}$ With half of the exercises including movement of the entire lower extremity during jumps, it would be expected that quadriceps and hamstrings RTD would have increased following plyometric training. However, in the current study, a statistically significant difference was not observed from pretraining to posttraining for any of the quadriceps or hamstrings RTD time windows but did show improvement in the plyometric intervention group, which indicated that plyometric training did not change the RTD of knee extensors. In contrast,

Aagaard et al observed knee extension contractile RTD increases through different time windows following a 14-week, heavyresistance, strength-training program. ${ }^{20} \mathrm{An}$ extended strengthening program caused an increased neuromuscular activation. Gruber and Gollhofer observed increased RTD before $50 \mathrm{~ms}$ following a four-week sensorimotor training. ${ }^{25}$ The RTD measurement by Gruber and Gollhofer ${ }^{25}$ was performed during isometric leg press action compared with other studies, which utilized isometric knee extension action. ${ }^{20,23}$ Gruber and Gollhofer observed significant changes in RTD during the 0 to $30 \mathrm{~ms}$ and 0 to $50 \mathrm{~ms}$ time windows but not during the 0 to $100 \mathrm{~ms}$ window. ${ }^{25}$ Their training increased RTD during the early phase. ${ }^{25} \mathrm{In}$ our study, the training used had rapid and explosive type exercises, which should increase the RTD during the earlier phase. Resistance training is the closest level of training to plyometrics that was used to determine change in RTD. The current study may not have shown an increase in RTD because the plyometric training was not vigorous enough for the participants to cause a neuromuscular adaptation.

In the current study, knee extension and knee flexion RTD was not different between groups. RTD has been used as a screening tool to determine deficits in quadricep and hamstring muscles prior to a soccer season in female athletes. ${ }^{21}$ The RTD hamstringto-quadricep ratios were $37 \%$ and $48 \%$ lower in the 2 women who suffered noncontact $A C L$ injuries during the season compared with the mean healthy female group. The RTD H:Q ratio deficit was observed during the first 50 ms of initial contraction, which is within the time window of the incident of noncontact $A C L$ injuries. ${ }^{22}$ In the current study, plyometric training did not increase the RTD, thus not facilitating the protective effects of improvements in the RTD. This plyometric training program did not increase the muscle activation around the knee.

(c) The Internet Journal of Allied Health Sciences and Practice, 2018 
Furthermore, vertical jump measurement was used to evaluate functional performance following the intervention. No significant vertical jump improvements were observed between groups but were observed as a significant preintervention-to postintervention main effect. In contrast to our findings, vertical jump was shown to increase following a plyometric training of longer durations of 8 weeks and 12 weeks. ${ }^{29,30}$ Vertical jump is one performance measure that typically increases following plyometrics. ${ }^{8-10}$ In the current study, the plyometric training program was only 6 weeks long. We observed a non-significant increase in the mean vertical jump measurement in the plyometric training group of $2.78 \mathrm{~cm}$ when compared with a control group that only increased by $1.10 \mathrm{~cm}$. Possible reasons for no statistically significant differences may have been related to the plyometric training not challenging the participants enough or that the control group might have been performing at a higher training level than was previous reported before starting the study. If this plyometric program lasted longer than 6 weeks, then we may have observed a significant increase in vertical jump in the plyometric training group.

One limitation in this study was not monitoring which physical activities the control group was performing during the intervention. Participants were relied upon for self-reporting of compliance with the study's exclusion criteria. In addition, a healthy control group was utilized during this experiment; there might be a different response in an ACL post-surgical population. Further research is needed to determine if this plyometric training component or other components from an ACL injury prevention program would be more effective on RTD in the lower extremity or vertical jump.

\section{Recommendation for Clinical Practice}

A stand-alone use of plyometric exercises from an ACL injury prevention program did not increase the performance of RTD for plantar flexion, knee extension, or knee flexion. Based on this study, clinicians should use the entire injury prevention program that has been recommended and not just select portions from the program, such as plyometric exercises, to show change. In addition, based on findings, 6 weeks of plyometric training from an isolated ACL injury prevention program should not be used to increase the vertical jump of healthy, active women.

\section{REFERENCES:}

1. Saez-Saez de Villarreal E, Requena B, Newton R. Does plyometric training improve strength performance? A Meta-Analysis. J Sci Med Sport. 2010;13:513-22. [PMID: 19897415]

2. Markovic G, Mikulic P. Neuro-musculoskeletal and performance adaptations to lower-extremity plyometric training. Sports Med. 2010;40(10):859-95. [PMID: 20836583]

3. Asmussen E, Bonde-Petersen F. Storage of elastic energy in skeletal muscles in man. Acta Physiol Scand. 1974;91:385-92. [PMID: 4846332]

4. Anderson F, Pandy M. Storage and utilization of elastic strain energy during jumping. J Biomech. 1993;26(12):141327. [PMID: 8308046]

5. Bosco C, Komi P. Potentiation of the mechanical behavior of the human skeletal musclethrough prestretching. Acta Physiol Scand. 1979;106:467-72. [PMID: 495154]

6. Bosco C, Ito A, Komi V, Luthanen P, Rahkila P, et al. Neuromuscular function and mechanical efficiency of human leg extensor muscles during jumping exercises. Acta Physiol Scand. 1982;114:543-50. [PMID: 7136782]

7. Aagaard P. Training-induced changes in neural function. Exerc Sport Sci Rev. 2003;31(2):61-7. [PMID 12715968]

8. Avela J, Finni J, Komi P. Excitability of the soleus reflex arc during intensive stretch-shortening cycle exercise in two power-trained athlete groups. Eur J Appl Physiol. 2006;97:486-93. [PMID: 16763835]

9. Avela J, Komi P. Reduced stretch reflex sensitivity and muscle stiffness after long-lastingstretch- shortening cycle exercise in humans. Eur J Appl Physiol. 1998;78:403-10. [PMID: 9809840]

10. Hakkinen $\mathrm{K}$, Komi $\mathrm{P}$, Alen M. Effect of explosive type strength training on isometric force-and relaxation-time, electromyographic and muscle fibre characteristics of leg extensor muscles. Acta Physiol Scand. 1985;125:587-600. [PMID: 4091002]

11. Hewett $T$, Lindenfeld $T$, Riccobene $J$, Noyes $F$. The effect of neuromuscular training on the incidence of knee injury in female athletes: a prospective study. Am J Sports Med. 1999;27:699- 706. [PMID: 10569353]

12. Mandelbaum B, Silvers H, Watanabe D, Knarr J, Thomas S, Griffin L, et al. Effectiveness of a neuromuscular and proprioceptive training program in preventing anterior cruciate ligament injuries in female athletes: 2-year follow-up. Am J Sports Med. 2005;33:1003-10. [PMID: 15888716]

13. Gilchrist J, Mandelbaum B, Melancon H, Ryan G, Silvers H, et al. A randomized controlled trial to prevent noncontact anterior cruciate ligament in female collegiate soccer players. Am J Sports Med. 2008;36:1476-83. [PMID: 18658019]

14. Lim B, Lee Y, Kim J, An K, Yoo J, Kwon Y. Effects of sports injury prevention training on the biomechanical risk factors of anterior cruciate ligament injury in high school female basketball players. Am J Sports Med.

(c) The Internet Journal of Allied Health Sciences and Practice, 2018 
2009;37(9):1728-34. [PMID: 19561174]

15. Vescovi J, VanHeest J. Effects of an anterior cruciate ligament injury prevention program on performance in adolescent female soccer players. Scand J Med Sci Sports. 2010;20:394-402. [PMID: 19558381]

16. Hewett T, Stroupe A, Nance T, Noyes F. Plyometric training in female athletes: decreased impact forces and increased hamstring torques. Am J Sports Med. 1996;24(6):765-73. [PMID: 8947398]

17. Griffin L, Albohm M, Arendt E, Bahr R, Beynnon B, et al. Understanding and preventing noncontact anterior cruciate ligament injuries. Am J Sports Med. 2006;34(9):1512-32. [PMID: 16905673]

18. Hewett T, Ford K, Myer G. Anterior cruciate ligament injuries in female athletes: part 2 a meta- analysis of neuromuscular interventions aimed at injury prevention. Am J Sports Med. 2006;34:490-8. [PMID: 16382007]

19. Yoo J, Lim B, Ha M, Lee S, Oh S, et al. A meta-analysis of the effect of neuromuscular training on the prevention of the anterior cruciate ligament injury in female athletes. Knee Surg Sports Traumatol Arthrosc. 2010;18:824-30. [PMID: 19760399]

20. Aagaard P, Simonsen E, Andersen J, Magnusson P, Dyhre-Poulsen P. Increased rate of force development and neural drive of human skeletal muscle following resistance training. J Appl Physiol. 2002;93:1318-26. [PMID: 12235031]

21. Zebis $M$, Andersen L, Ellingsgaard $H$, Aagaard P. Rapid hamstring/quadriceps force capacity in male vs. female elite soccer players. J Strength Cond Res. 2011;25(7):1989-93. [PMID: 21701286]

22. Krosshaug T, Nakamae A, Boden B, Engebretsen L, Smith G, et al. Mechanisms of anterior cruciate ligament injury in basketball: video analysis of 39 Cases. Am J Sports Med. 2007;35:359- 67. [PMID: 17092928]

23. Andersen L, Andersen J, Zebis M, Aagaard P. Early and late rate of force development: differential adaptive responses to resistance training? Scand J Med Sci Sports. 2010;20:162-9. [PMID: 19793220]

24. Del Balso C, Cafarelli E. Adaptations in the activation of human skeletal muscle induced by short- term isometric resistance training. J Appl Physiol. 2007;103:402-11. [PMID: 17446407]

25. Gruber M, Gollhofer A. Impact of sensorimotor training on the rate of force developmentand neural activation. Eur J Appl Physiol. 2004;92:98-105. [PMID: 15024669]

26. Myer G, Ford K, McLean S, Hewett T. Effects of plyometric versus dynamic stabilization and balance training on lower extremity biomechanics. Am J Sports Med. 2006;34:445-55. [PMID: 16282579]

27. Andersen L, Aagaard P. Influence of maximal muscle strength and intrinsic muscle contractile properties on contractile rate of force development. Eur J Appl Physiol. 2006;96:46-52. [PMID: 16249918]

28. Bosco C, Tihanyi J, Komi P, Fekete G, Apro P. Store and recoil of elastic energy in slow and fast types of human skeletal muscles. Acta Physiol Scan. 1982;116:343-9. [PMID: 7170997]

29. Kubo K, Morimoto M, Komuro T, Yata H, Tsunoda N, et al. Effects of plyometric and weight training on muscle-tendon complex and jump performance. Med Sci Sports Exerc. 2007;39(10):1801-10. [PMID: 17909408]

30. Wu Y, Lien Y, Lin K, Shih T, Wang T, Wang H. Relationship between three potentiation effects of plyometric training and performance. Scand J Med Sci Sports. 2010;20:80-6. 